\title{
Fístula de líquido cefalorraquídeo después de hisopado nasofaríngeo en pandemia COVID-19. A propósito de dos casos
}

\section{Cerebrospinal fluid leak after nasopharyngeal swab testing for COVID-19. A report of two cases}

\author{
Matías Gómez G. ${ }^{1,2,3}$, Carolina Oliva G. ${ }^{3,}$ Francisca Montoya S. ${ }^{4,5}$, \\ David Rojas Z. ${ }^{6,7}$, José Tomás Zemelman L. ${ }^{3}$
}

${ }^{1}$ Unidad de Otoneurología, Instituto de Neurocirugía Dr. Asenjo. Santiago, Chile. ${ }^{2}$ Departamento de Otorrinolaringología, Clínica Alemana de Santiago. Santiago, Chile.

${ }^{3}$ Departamento de Otorrinolaringología, Universidad de Chile. Santiago, Chile. ${ }^{4}$ Servicio Neurorradiología, Universidad de Valparaíso. Valparaíso, Chile. ${ }^{5}$ Servicio de Neurorradiología, Instituto de Neurocirugía Dr. Asenjo. Santiago,

Chile.

${ }^{6}$ Departamento de Neurocirugía, Clínica Alemana de Santiago. Santiago, Chile.

${ }^{7}$ Servicio de Neurocirugía, Instituto de Neurocirugía Dr. Asenjo. Santiago,

Chile.

Los autores declaran no tener conflictos de interés.

Recibido el 23 de marzo de 2021. Aceptado el 9 de abril de 2021.

Correspondencia: Matías Gómez G.

Unidad de Otoneurología Instituto de Neurocirugía Dr. Asenjo Avenida José Manuel Infante 553, Providencia. Santiago, Chile. Email: drmatiasgomez@gmail.com

\section{Resumen}

Uno de los pilares fundamentales en el manejo de la pandemia por SARS-CoV2 es la detección temprana de la presencia del virus en pacientes. El método más utilizado es mediante hisopado nasofaríngeo para amplificar ácidos nucleicos mediante reacción en cadena de polimerasa (PCR). Las complicaciones asociadas a la técnica de hisopado aún no están completamente caracterizadas. Hasta ahora hay un caso reportado internacionalmente de fístula de líquido cefalorraquídeo poshisopado nasofaríngeo. Presentamos dos casos de fístula posterior a dicho examen: el primer caso un paciente de género femenino con sospecha de hipertensión intracraneal idiopática, cuya brecha se reparó quirúrgicamente; el segundo caso un paciente de género masculino con antecedente de hidrocefalia y meningitis neonatal que, al estudio por rinorraquia, se encuentra un meningoencefalocele en el receso frontal derecho, también reparado quirúrgicamente.

Palabras clave: COVID-19, hisopado nasofaríngeo, fístula de líquido cefalorraquídeo.

\begin{abstract}
One of the cornerstones in the management of coronavirus pandemic is the early identification of virus presence in patients. The most used test is the nasopharyngeal swab, used to amplify nucleic acids through polymerase chain reaction. Complications with this test have not been completely characterized. Until now, only one international report of cerebrospinal fluid leak has been reported. We present two cases of leak after nasopharyngeal swab test: the first case corresponded to an adult feminine gender patient with suspected idiopathic intracranial hypertension, whose gap was surgically repaired; the second case adult male patient with medical history of hydrocephalus and neonatal meningitis who was further studied for rhinoliquorrhea that showed a meningoencephalocele occupying the right frontal recess.
\end{abstract}

Keywords: COVID-19, nasal swab test, nasopharyngeal test, cerebrospinal fluid leak. 
pandemia es el diagnóstico oportuno, para ello se requiere detectar la presencia del ARN viral a través de amplificación de ácidos nucleicos, más comúnmente mediante reacción en cadena de polimerasa (PCR por sus siglas en inglés) de muestras obtenidas de la vía aérea superior a través de hisopado nasofaríngeo, nasal anterior y de cornete medio ${ }^{3}$. La técnica adecuada para la toma de este examen ha sido bien descrita ${ }^{4} y$ se recomienda su revisión para disminuir los posibles efectos adversos.

Las complicaciones asociadas a la técnica de hisopado aún no están completamente caracterizadas. Un estudio reciente con un total de 11.476 hisopados nasales y de orofaringe reporta solo 3 casos de complicaciones $(0,026 \%)$ : 2 pacientes con ruptura de la punta del hisopo y un caso de luxación espontánea de la articulación temporomandibular al abrir la boca para el hisopado orofaríngeo ${ }^{1}$. En otra serie con 4.876 hisopados, 8 pacientes $(0,16 \%)$ presentaron complicaciones: 3 epistaxis anteriores que requirieron taponamiento, 3 casos de ruptura e impactación del hisopo, un paciente con desarrollo de absceso septal y otro con sangrado severo anteroposterior posiblemente proveniente de la arteria etmoidal anterior que requirió cauterización quirúrgica ${ }^{5}$.

Sullivan y cols. ${ }^{6}$ reportan el primer caso de fístula de líquido cefalorraquídeo (LCR) a causa de hisopado nasofaríngeo para detectar SARS-CoV-2, sin embargo, la paciente poseía un encefalocele etmoidal preexistente. Los autores hipotetizan que el procedimiento en sí mismo no es capaz de generar una lesión en la base de cráneo, más bien, es necesaria una lesión preexistente para que se genere una fístula de LCR.

Hasta la fecha en nuestro país se han tomado más de 10.600.000 exámenes por sospecha de COVID-197. A través del siguiente artículo reportamos los primeros casos de fístula de LCR traumática en nuestro país y, según nuestro conocimiento, el segundo estudio reportado a nivel mundial. Ambos casos cuentan con consentimiento informado por parte de los pacientes.

\section{Caso Clínico 1}

Paciente de género femenino, 49 años, sin antecedentes mórbidos previos conocidos. Se realiza hisopado nasofaríngeo para PCR SARS-CoV-2. Inmediatamente posterior a la toma de examen, empieza con descarga nasal de líquido transparente que aumenta al inclinarse. El líquido fue positivo para la presencia de $\beta 2$-transferrina, confirmando que corresponde a LCR. A la endoscopía nasal se encuentra brecha en etmoides anterior (Figuras 1A y B). Se toma cisternografía con tomografía computada (TC) (Figura 1C) con brecha a nivel de lamela lateral derecha en corte coronal, sin otras lesiones evidentes. Además, tiene hallazgos sugerentes de hipertensión intracraneana a las imágenes como silla turca vacía y cavum de Meckel prominente.

La fístula de LCR fue reparada mediante

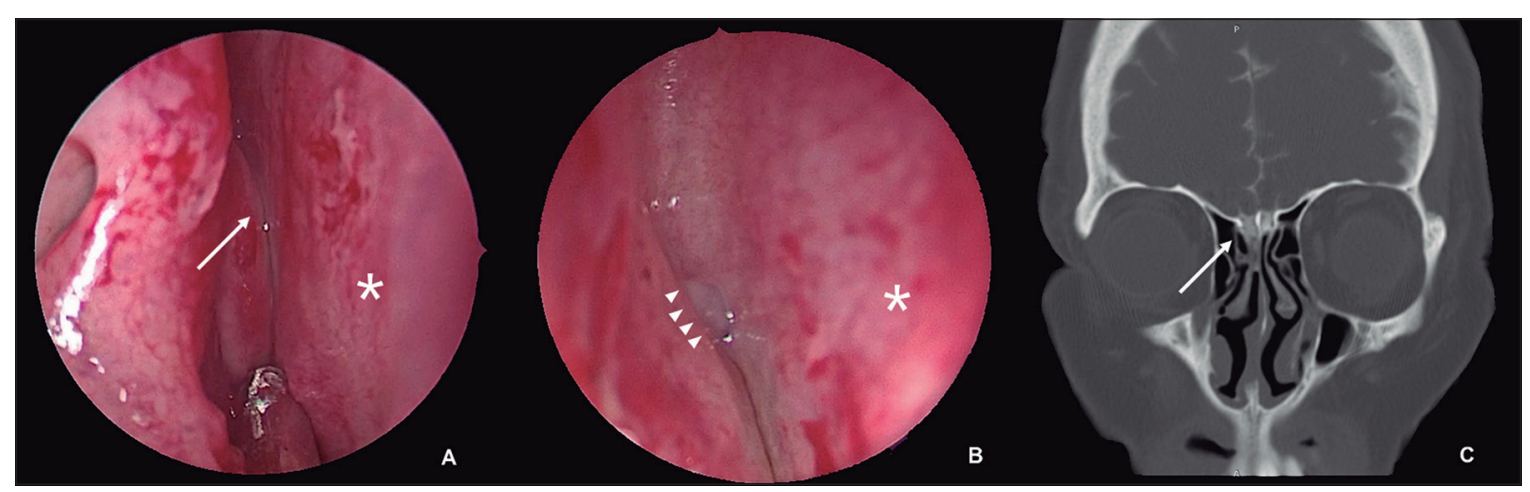

Figura 1. Endoscopía y tomografía computada de caso clínico 1. A y B: Imágenes endoscópicas por fosa nasal derecha de sitio de fístula de líquido cefalorraquídeo en lamela lateral. Flecha blanca: sitio de fístula. Asterisco: tabique nasal. Puntas de flechas: brecha con fístula activa de LCR. C: Cisternotomografía computada en corte coronal, flecha blanca: brecha osteomeníngea en lamela lateral derecha con salida activa de líquido cefalorraquídeo con contraste. 
cirugía endoscópica nasal, realizando un selle multicapa con grasa abdominal, mucosa y hueso de cornete medio derecho. La medición precoz de presión de apertura de LCR a nivel lumbar fue de $16 \mathrm{cmH}_{2} \mathrm{O}$, en rango normal, sin aumento de presión intracraneal. Se realiza una evaluación neurooftalmológica que no evidencia signos de hipertensión en su nervio óptico. Una nueva toma de presión de apertura se realiza al mes del cierre endoscópico de fístula de LCR, evidenciando una presión de $28 \mathrm{cmH}_{2} \mathrm{O}$, por lo que se indica manejo de su hipertensión intracraneana idiopática.

\section{Caso Clínico 2}

Paciente de género masculino de 33 años con antecedente de meningitis neonatal, hidrocefalia con derivación ventriculoperitoneal. Durante pandemia COVID-19 cursa con neumonía aspirativa, siendo hospitalizado, donde se toma hisopado nasofaríngeo buscando etiología a su neumonía. Evoluciona al quinto día luego de la toma de examen con rinorraquia por fosa nasal derecha que incrementa al inclinarse, también aumentando flujo con maniobra de Valsalva. Se mantiene con rinorraquia por meses hasta que consulta a otorrinolaringología, donde al examen con nasofibroscopía evidencia salida de líquido claro por meato medio dando positivo para la presencia de $\beta 2$-transferrina, compatible con LCR. Dado los hallazgos, se estudia con TC mostrando dehiscencia de la fóvea etmoidal derecha con presencia de tejido blando en el receso del seno frontal derecho. Al complementar con resonancia magnética (RM), se describe parénquima frontobasal en el receso frontal derecho compatible con un meningoencefalocele (Figura 2).

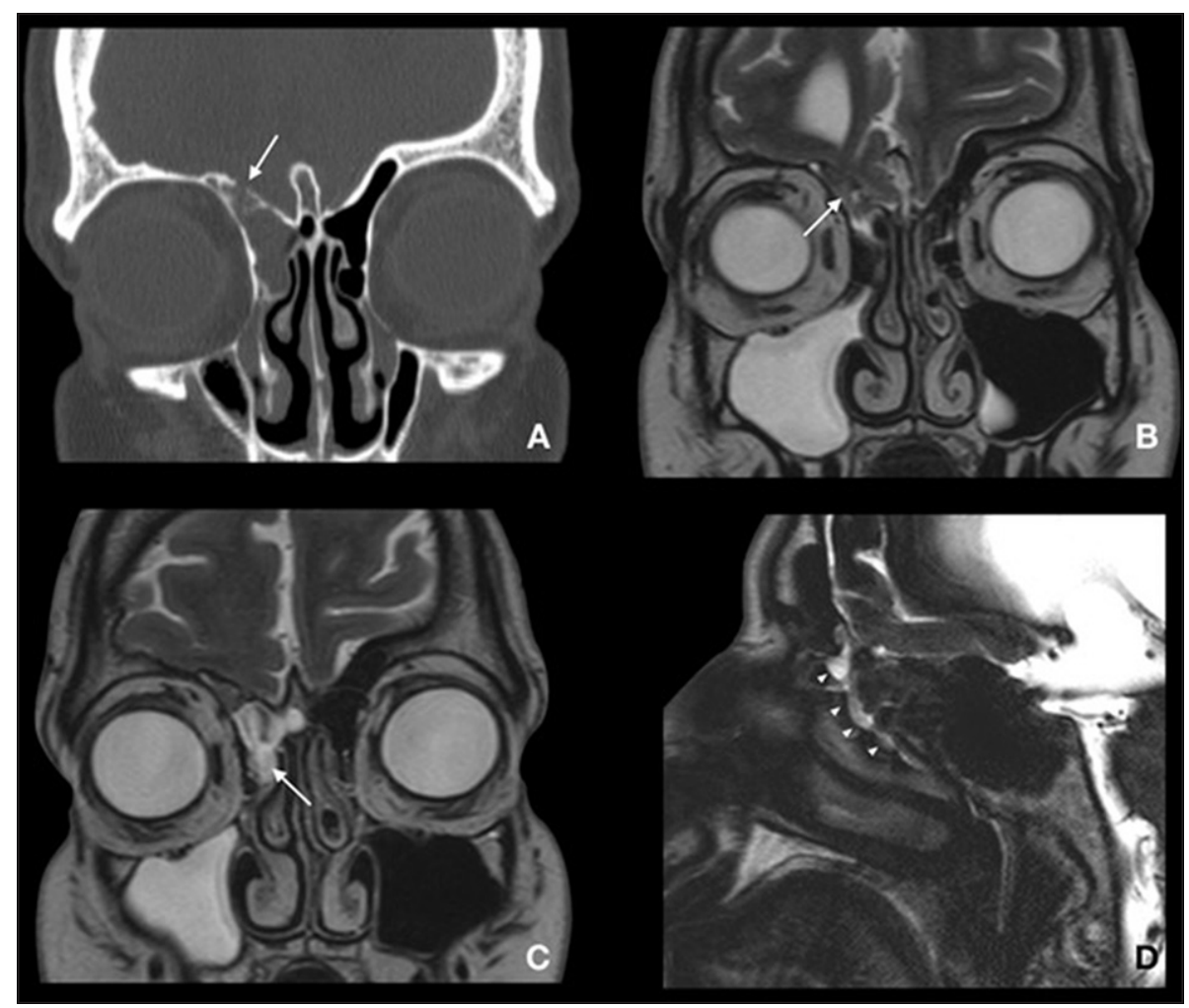

Figura 2. Tomografía computada y resonancia magnética de caso clínico 2. A: Tomografía computada de cavidades paranasales corte coronal. Flecha blanca: dehiscencia ósea en fóvea etmoidal derecha con presencia de tejido blando. B y C: Resonancia magnética corte coronal T2WI mostrando meningoencefalocele de parénquima frontobasal derecho (flecha en B) con presencia de LCR Ilenando receso frontal derecho (flecha en C). D: Resonancia magnética corte sagital T2WI. Puntas de flecha: trayecto de líquido cefalorraquídeo a través del receso frontal derecho hasta infundíbulo. 
Dados los hallazgos se decide realizar vía endoscópica una resección de pequeño meningocele y posterior reparación multicapas con grasa abdominal, mucosa, hueso de cornete medio y placas de plasma rico en plaquetas (como tejidos autólogos) reforzando en superficie con materiales sintéticos logrando un cierre satisfactorio.

\section{Discusión}

En Chile al momento de realizar este artículo se han realizado más de diez millones de hisopados nasofaríngeos para PCR, sin reportes aún de complicaciones. Es importante recordar ciertos factores anatómicos nasales que, en la toma del hisopado nasofaríngeo, así como en la cirugía endoscópica sinusal como de la base de cráneo, nos permiten evitar complicaciones $^{8}$ :

1) En el eje sagital, la base de cráneo de anterior a posterior va descendiendo, por lo que nuestra base de cráneo a nivel esfenoidal/ planum se encuentra a un nivel más bajo respecto a la base de cráneo anterior.

2) La porción anterior es la zona más delgada, delicada e irregular de toda la base de cráneo, esto dado fundamentalmente por dos factores como son:

a) Lamela lateral, fóvea y lámina cribiformes muy delgadas.

b) En lámina cribiforme la entrada de las fibras olfatorias desde la mucosa nasal hacia el nervio y bulbo olfatorio, representan una zona de hueso con orificios verdaderos donde podemos encontrar transudado o fístulas por representar zonas de menor resistencia.

Estos dos casos corresponden a los primeros en ser reportados en Chile y segundos a nivel internacional de fístula de LCR. El primer caso reportado poseía una predisposición anatómica al igual que nuestro segundo caso, un encefalocele que aumentaba el riesgo de trauma y fístula con el hisopado ${ }^{6}$. En el estudio de fístulas de LCR, tanto espontáneas como traumáticas, es importante realizar un análisis exhaustivo de la historia clínica y de las imágenes de los pacientes intentando identificar etiologías que la expliquen.
Los pacientes con síndromes de hipertensión intracraneanas idiopáticas presentan fluctuaciones en las presiones intracraneales, por lo que muchas veces es necesario repetir las mediciones de presión de apertura mediante punción lumbar si sospechamos la presencia de esta patología. Creemos necesario preguntar por patología nasal como tumores o cirugías realizadas previo a cualquier hisopado nasofaríngeo. El hisopo debe ser introducido y dirigido en un ángulo paralelo al piso nasal y paladar hacia la rinofaringe, evitando que el paciente hiperextienda exageradamente la cabeza para alejarse de la base del cráneo 9 . Eventualmente podría realizarse toma de examen por otorrinolaringólogo en casos seleccionados y bajo visión endoscópica, como también evaluar la posibilidad de realizar hisopado orofaríngeo o PCR en saliva como recomienda también el Centro para el Control y Prevención de Enfermedades de Estados Unidos (CDC por sus siglas en inglés) $)^{3}$.

\section{Conclusión}

El hisopado nasofaríngeo es un examen seguro, pero no exento de posibles complicaciones. El conocimiento preciso de la anatomía nasal como también de los antecedentes mórbidos y quirúrgicos se hacen importantes en la valoración de cada paciente a quienes se debe realizar este examen.

Recomendamos que quienes indican o toman hisopados nasales o nasofaríngeos pregunten dirigidamente sobre cirugías nasales o de base de cráneo previas para evitar complicaciones. En caso de dudas, cambiar de hisopado nasofaríngeo a orofaríngeo u otro tipo de muestra como salival si están las condiciones, como también solicitar ayuda al otorrinolaringólogo.

\section{Bibliografía}

1. Föh B, Borsche M, Balck A, et al. Complications of nasal and pharyngeal swabs-a relevant challenge of the COVID-19 pandemic? Eur Respir J. doi: 10.1183/13993003.04004-2020.

2. Ministerio de Salud G de C. A seis meses del primer caso de COVID-19, el 93\% de los pacientes se han 
recuperado - Ministerio de Salud - Gobierno de Chile. Published 2020. https://www.minsal.cl/a-seismeses-del-primer-caso-de-covid-19-el-93-de-lospacientes-se-han-recuperado/.

3. CDC. Interim Guidelines for Clinical Specimens for COVID-19 | CDC. Centers for Disease Control and Prevention. Published 2020. https://www.cdc.gov/ coronavirus/2019-nCoV/lab/guidelines-clinicalspecimens.html.

4. Coden E, Russo F, Arosio AD, Castelnuovo P, Karligkiotis A, Volpi L. Optimum Nasooropharyngeal Swab Procedure for COVID-19: Step-by-Step Preparation and Technical Hints. Laryngoscope. 2020;130(11):2564-2567. doi: 10.1002/ lary.29010.

5. Fabbris C, Cestaro W, Menegaldo A, et al. Is oro/ nasopharyngeal swab for SARS-CoV-2 detection a safe procedure? Complications observed among a case series of 4876 consecutive swabs. Am J
Otolaryngol-Head Neck Med Surg. 2021;42(1):102758. doi: 10.1016/j.amjoto.2020.102758.

6. Sullivan CB, Schwalje AT, Jensen M, et al. Cerebrospinal Fluid Leak After Nasal Swab Testing for Coronavirus Disease 2019. JAMA Otolaryngol Neck Surg. 2020;146(12):1179. doi: 10.1001/ jamaoto.2020.3579.

7. Ministerio de Salud G de C. Se reportan 4.201 nuevos casos y tasa de positividad es de 7,77\% - Ministerio de Salud - Gobierno de Chile. Published 2021. www. minsal.cl

8. Gómez Galarce M, Yanez-Siller JC, Carrau RL, et al. Endonasal anatomy of the olfactory neural network: Surgical implications. Laryngoscope. 2018;128(11):2473-2477. doi: 10.1002/lary.27194.

9. Marty FM, Chen K, Verrill KA. How to Obtain a Nasopharyngeal Swab Specimen. Ingelfinger JR, ed. N Engl J Med. 2020;382(22):e76. doi: 10.1056/ nejmvcm2010260. 